\title{
Falling in Acute Mental Health Settings for Older People: Who falls, where, when and why?
}

Victor $C^{1}$, Dickinson $A^{2^{*}}$, Narayanan $V^{3}$, Simpson $C^{2}$, Griffiths $C^{3}$ and Humphrey $D^{3}$

1 School of Health Sciences and Social Care, Brunel University, Uxbridge, Middlesex, UK

2Centre for Research in Primary and Community Care, University of Hertfordshire, Hatfield, Hertfordshire, UK

3Oxford Health NHS Foundation Trust, Fulbrooke Centre, Churchill Hospital Site, Headington, Oxford, UK

*Correspondence author: Angela Dickinson, Centre for Research in Primary and Community Care, University of Hertfordshire, Hatfield, Hertfordshire, UK, Tel: 01707 285993; Email: a.m.dickinson@herts.ac.uk

Rec date: Mar 28, 2014; Acc date: Sep 26, 2014; Pub date: Sep 28, 2014

Copyright: ( 2014 Dickinson A et al. This is an open-access article distributed under the terms of the Creative Commons Attribution License, which permits unrestricted use, distribution, and reproduction in any medium, provided the original author and source are credited.

\section{Abstract}

Falls, slips and trips are a major patient safety concern in hospital settings accounting for 26 per cent of all reported patient safety incidents in England. Mental health conditions and their treatments add further to fall risk but we have little information regarding who falls, where and when within mental health settings.

Methods: This paper presents an overview of the pattern of falls by older patients within an in-patient mental health setting in the South of England using routine records completed by staff when a fall occurs. 920 fall reports over three years were analysed, and 7 focus groups were undertaken with ward staff to explore how staff understood falls and their experiences of using the falls reporting system.

Results: In terms of diagnosis $40 \%$ of fallers had a primary functional diagnosis, $46 \%$ an organic mental health diagnosis ( $14 \%$ non-specific diagnosis), average age was 81.7 years (range 59 to 99 years; SD 8.3 ) and $57 \%$ were female. Approximately one quarter, $27 \%$, of falls were observed by staff. Falls were not evenly distributed across either day of week or time of day, with peak times for falls on Tuesday and Saturday and morning (7-8 and 9-10am) and subsidiary peaks between noon and $1 \mathrm{pm}$ and early evening $(5-6 \mathrm{pm})$. Almost half of falls occurred in private spaces in the ward such as bedrooms, and $42 \%$ in public spaces such as sitting rooms. However $60 \%$ of falls in public spaces were unseen. Reporting in these settings was problematic for staff and patients were sometimes described as placing themselves on the floor as a consequence of their mental health condition. The average time to first fall was 5 weeks.

Conclusions: Routine mapping of falls could be undertaken at ward and organization level and contribute to better understanding of the local factors contributing to falls. Exploring incident report data in focus groups with staff helped us and them to interpret the data and to understand some of the decision making staffs engage in everyday when reporting falls.

\section{Key words:}

Older people; Falls; Mental health; Acute mental health care setting

\section{Introduction}

It is well established that the prevalence and incidence of falls increases with age [1]. For those living in the community about a third of those aged 65 and over will fall annually [2] with the resultant consequences of physical injury and compromised quality of life, anxiety and depression and restricted mobility $[3,4]$. However falls are not only experienced by older people living at home but are also experienced by older people being treated in hospitals and living in residential or nursing homes where falls, slips and trips are a major patient safety concern accounting for 26 per cent of all reported patient safety incidents. Within hospitals in England and Wales there are approximately 282,000 falls reported annually, with around 840 resulting in fractured hips, 550 in other types of fracture and 30 intracranial injuries. The majorities of those falling in acute hospitals are aged $65+$ and are characterized by advanced age, significant co- morbidity and dementia or delirium. As well as injuries, patients experiencing a fall also stay longer in hospital, even those who experience a non-injurious fall [5]. Guidelines from the UK National Institute for Health and Care Excellence [6] support the identification of patients 'at risk' of falls on admission to hospital [those aged 65+ or aged 50 and over with a condition known to increase fall risk] and has identified appropriate interventions to prevent/reduce falls risk in hospital patients. Falls within hospital settings are not confined to the UK and other health care systems in a range of jurisdictions including Australia [7], Canada [8], the United States [9] and Europe (eg. [10] have all identified this as a patient safety issue and offered guidance on falls risk assessment as well as interventions aimed at falls reduction and/or prevention.

Mental health problems, most notably dementia [11] but also other conditions such as anxiety and depression [12], are a key risk factor for falls in the community, hospitals and care homes [13]. Furthermore, with falls in these settings a significant patient safety issue $(36,000$ falls annually in England alone [14]), it is surprising that few researchers 
Citation: Victor C, Dickinson A, Narayanan V, Simpson C, Griffiths C, Humphrey D (2014) Falling in Acute Mental Health Settings for Older People: Who falls, where, when and why?. J Gerontol Geriat Res 3: 173. doi:10.4172/2167-7182.1000173

Page 2 of 8

have sought to investigate the issues of falls for older people being cared for in mental health.

Heslop [15], studied two mental health settings in Australia, and concluded that the numbers of falls incidents were underreported. They observed a variation across their research sites in the timing of falls with one where-falls occurred most frequently between 21.00 and 24.00, and 18.00-19.00 hours whilst on the other the peak time for falls incidents was between 09.00 and 15.00. Hill et al. 2010 [16], found that fall incident reports captured about 75.5 per cent of falls events. They suggested that falls may be less likely to be reported during busy times of day, so between 06.00 and 10.00 and 14.00 and 18.00. Falls which resulted in moderate to severe injury were more likely to be reported and those resulting in minor injury, near misses, and subsequent falls being less likely to be recorded. Heslop et al. 2012 [15] argue that a high level of reporting of the low-level injury falls and near misses indicates good reporting practice and the presence of a noblame safety culture. Given the number of falls that occur in mental health settings there are few studies evaluating the effectiveness of falls interventions for older people with mental health problems at risk of falls or who have fallen when compared with acute hospital settings. A systematic review by Bunn et al. [17] identified only 17 studies that had evaluated falls assessment and reduction/prevention interventions in mental health settings and concluded that there was insufficient robust evidence to support practitioners to implement interventions that prevent people with mental health problems from falling.

Given these key gaps in our knowledge base we undertook a study that sought:- (a) To explore how fall risk, prevention and management is understood and experienced in everyday practice by patients, family carers and staff, in inpatient mental health settings providing care for older people and (b) to identify how assessment tools, guidelines and policy for fall prevention are used in these care environments. In this paper we present an overview of the pattern of falls by older patients within in-patient mental health settings using routine records completed by staff when a fall occurs. We focus upon the number of falls, the characteristics of those who fall and the temporal and spatial location of falls and consider the 'reasons' why older people were falling.

\section{Materials and Methods}

Our study site consisted of 5 wards providing care for older people in the Mental Health service of a large NHS Trust in Southern England. Wards were dispersed across 2 counties in 3 locations; 3 provided care for patients with mixed diagnosis, 1 for people with dementia, 1 for functional illness; 2 were single sex. At the time of the study 4 wards had 17 beds each and one was slightly larger with 21 beds.

For the overall study we used a case study approach that encompassed a range of inter-related data collection methods consisting of:- (a) Documentary analysis: All mental health Trusts in England and Health Boards in Wales were asked to send copies of their fall policies so we could document the extent to which evidencebased guidelines influenced local policies. This involved the analysis of 46 falls policies of which 44 were from England and 2 from Wales; (b) Non-participant observation to explore ward routines, practices and use of space in order to build an understanding of the clinical setting. This involved 308 hours of direct observation covering both day and night and weekdays and weekends; (c) Analysis of fall incident reports (3 years) to determine where and when falls happened, causes and impact of falls on patients. This involved reviewing 920 fall reports for a 3 year period; (d) Patient tracking was used to explore patient's experiences of a fall, incorporating interviews with patients, key staff, relatives, case note review and follow up to discharge. This involved tracking 24 patients and interviews with 48 staff and 5 carers and Interviews and focus groups were used to explore approaches to falls policy interpretation and decision-making at strategic, operational and clinical levels involving 6 interviews with managers and 7 staff focus groups ( $\mathrm{n}=45$ staff). User involvement in the research process was provided by 1 focus group with carers and discussions with and formal feedback sessions with clinical staff and a range of other activities.

Within our study sites all falls experienced by patients were reported using a standard electronic form which consists of a number of 'drop down' menu boxes (for example the type of fall, the recordeddate/time) and free text boxes where location of the fall and a description of the incident and actions taken by staff following the fall are reported along with the cause of the fall as identified by the reporting staff member. Additionally staff report if the fall was observed by staff or the patient was 'found' on the floor. The design and content of the falls reporting form is determined at Trust levelthere is no nationally determined form-but the data collected are reported by the Trust to the regulating bodies. Since 1 April 2010 it is mandatory for NHS trusts in England to report all serious patient safety incidents (those resulting in permanent harm or death) to the Care Quality Commission. Date of birth, sex and ethnicity and NHS number-are recorded.

There are some examples of researchers using these types of routine falls reporting data to examine the pattern of falls within institutional settings. In an acute metropolitan hospital in Australia, Johnson et al. [18] reported that the average age of fallers in their study as 68.6 years; that the majority of falls were unwitnessed $(77 \%)$ and that $82 \%$ did not result in serious harm. In their study falls were most likely to be reported as occuring between 9-12 am and 1-5pm. We have identified two studies in Britain that analysised the routine falls report forms. Healey et al. [14] undertook an analysis of falls report forms for England and Wales for 12 months during 2007-8. This included patients of all ages cared for in all NHS settings including acute, community and mental health hospitals and day hospitals. They reported that most falls occured in in-patient areas (94\%); that only a minority were witnessed by staff and that approximately $4 \%$ resulted in serious/severe harm to the patient. The mean reported rate of falls was 4.8 per 1000 bed days for acute trusts and 2.1 for mental health trusts. Age was not reported on $47.5 \%$ of forms but, where it was, $82.6 \%$ of falls were accounted for by those aged $65+$. Falls were not equally distributed over time. A peak was observed for Tuesdays and a relative 'trough' on a Sunday and early morning (6am to 7am); midmorning (10-noon); lunch time (1-3pm) and early evening (7-8pm). Hignett et al. 2011 [19] undertook further analysis of these data by examining the reported 'causes' of falls recorded for older patients in acute and community hospitals for 12 months (2006-2007). Their focus was upon evaluating the cause of 'unwitnessed' falls for this population in bedrooms or toilets/bathrooms. They did not look at falls occurring in 'public' spaces. However missing data presented a challenge for these authors as $53 \%$ of fall reports provided no data about the 'cause' of the fall. Where they could attribute a cause to the fall $37 \%$ were determined to have been caused by extrinsic factors (eg. wet floors) and $63 \%$ to intrinsic patient related factors such as cognitive impairment, mobility problems etc. However none of these studies has looked at the key attributes of falls-the characteristics of fallers, the location of the fall, the reason for the fall and the location of the fall 
Citation: Victor C, Dickinson A, Narayanan V, Simpson C, Griffiths C, Humphrey D (2014) Falling in Acute Mental Health Settings for Older People: Who falls, where, when and why?. J Gerontol Geriat Res 3: 173. doi:10.4172/2167-7182.1000173

Page 3 of 8

explicitly focussing upon older adults in mental health settings. It is this evidence gap that this paper seeks to address.

Trust policy requires staff to complete an 'incident' form following every patient fall, irrespective of whether the fall was observed/not observed by staff. In addition, as per national guidelines, staff are encouraged to report trips, slips and near misses. The forms are completed as soon after the incident as is practicable. The forms were in an electronic format, being completed by staff on a computer. The incident form comprises a number of drop-down boxes which staff select from, along with boxes to enable narrative information and additional data about the fall to be provided. Incident reports are collated centrally after being checked by ward managers, and alerts of incidents are made electronically to various staff members- including staff responsible for safeguarding if necessary. We were given anonomised falls report data for 3 calendar years-2010, 2011 and 2012 which did not contain any patient identifying information (e.g. date of birth, gender). For 2012 we obtained further details of the individuals who fell by using the NHS number to identify the age, sex, diagnosis and length of stay of those who fell. This data linking was undertaken by one of the team $(\mathrm{VN})$ who is an NHS staff member. As this is an exploratory study and our data set has a limited number of fields, we use descriptive analysis to consider the number, type and causes of falls in the case study site and the outcome of falls across the 3 years (2010-2012) as well the time and day of the week that the fall was recorded as taking place. For our more detailed data set we focus upon the characteristics of those who fell and consider the time after admission that falls occured. We limit our analysis to Trust level as the sample size is insufficient to undertake meaningful comparisons across the five study wards.

\section{Results}

Our case study area had an overall falls rate of 2.9 per 1,000 bed days in 2012/13 which is comparable to the rate of 2.1 per 1000 reported by Healy et al. [13]. During the 3 years of our study a total of 920 falls were reported across the 5 wards included in the study. There were 290 reported falls in 2010 and 315 each for both 2011 and 2012. For 100 reports there was no identifying information. However for the 820 falls reports where staff used patient initials in their reports we can estimate that these represented 390 different individuals of whom 216 had only 1 fall recorded; so in our study approximately two thirds of patients fell once whilst one third were 'multiple fallers'.

\section{How did staff know a fall had occurred?}

Staff completed a free text box on the form to report how the fall had been identified and these narratives were coded by the research team. Only $27 \%$ of falls were observed by staff; the majority, $73 \%$, of falls were not observed by staff (see Table 1). Staff were made aware that there had been a fall through the patient being found on the floor and was presumed to have fallen but this was not seen by anyone; this accounted for 37 per cent of reported falls. Table 1 shows how staff became aware of falls as recorded in the incident forms. Typical comments written on the incident forms for these situations were as follows:- "Patient X was found sitting on the floor in her bedroom, appears to have fallen or slipped" and "Patient found on the floor, observed bump to left side of head, unsure how this injury was obtained". Staff reporting hearing a loud noise [20\%] as illustrated by the comment "Staff heard a big bang from (patient) room, Staff went to investigate and found (patient) on the floor between her bed and a stool".

\begin{tabular}{|l|l|l|}
\hline How staff became aware of a fall * & Frequency & Percent \\
\hline Found on floor & 341 & $37 \%$ \\
\hline Staff observed fall & 252 & $27 \%$ \\
\hline Heard loud noise & 184 & $20 \%$ \\
\hline Patient reported own fall & 56 & $6 \%$ \\
\hline Found wound or injury & 18 & $2 \%$ \\
\hline Patient reported fall of another patient & 17 & $2 \%$ \\
\hline Visitor reported fall & 9 & $1 \%$ \\
\hline Patient alarm/buzzer & 8 & $1 \%$ \\
\hline Not stated/unclear in report & 35 & $4 \%$ \\
\hline Total & 920 & $100 \%$ \\
\hline $\begin{array}{l}\text { *categories devised by the research team from free text recorded by staff on the } \\
\text { incident report form }\end{array}$ & \multicolumn{2}{|l}{} \\
\hline
\end{tabular}

Table 1: How staff became aware of falls (as recorded in incident reports)

\section{When do falls happen?}

Reported falls incidents were not equally distributed across the day of the week or time of day (Figures 1 and 2). A clear peak could be observed on Tuesdays, Saturdays and in the morning (7-8 and 9-10) with subsiduary peaks at lunch time (noon-1pm) and in the early evening (5-6pm).

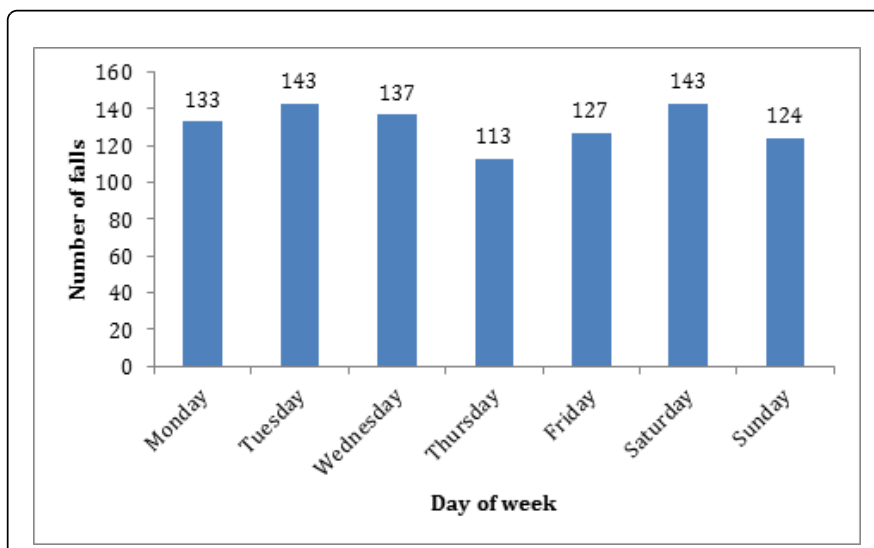

Figure 1: Number of falls reported on different days of the week 
Citation: Victor C, Dickinson A, Narayanan V, Simpson C, Griffiths C, Humphrey D (2014) Falling in Acute Mental Health Settings for Older People: Who falls, where, when and why?. J Gerontol Geriat Res 3: 173. doi:10.4172/2167-7182.1000173

Page 4 of 8

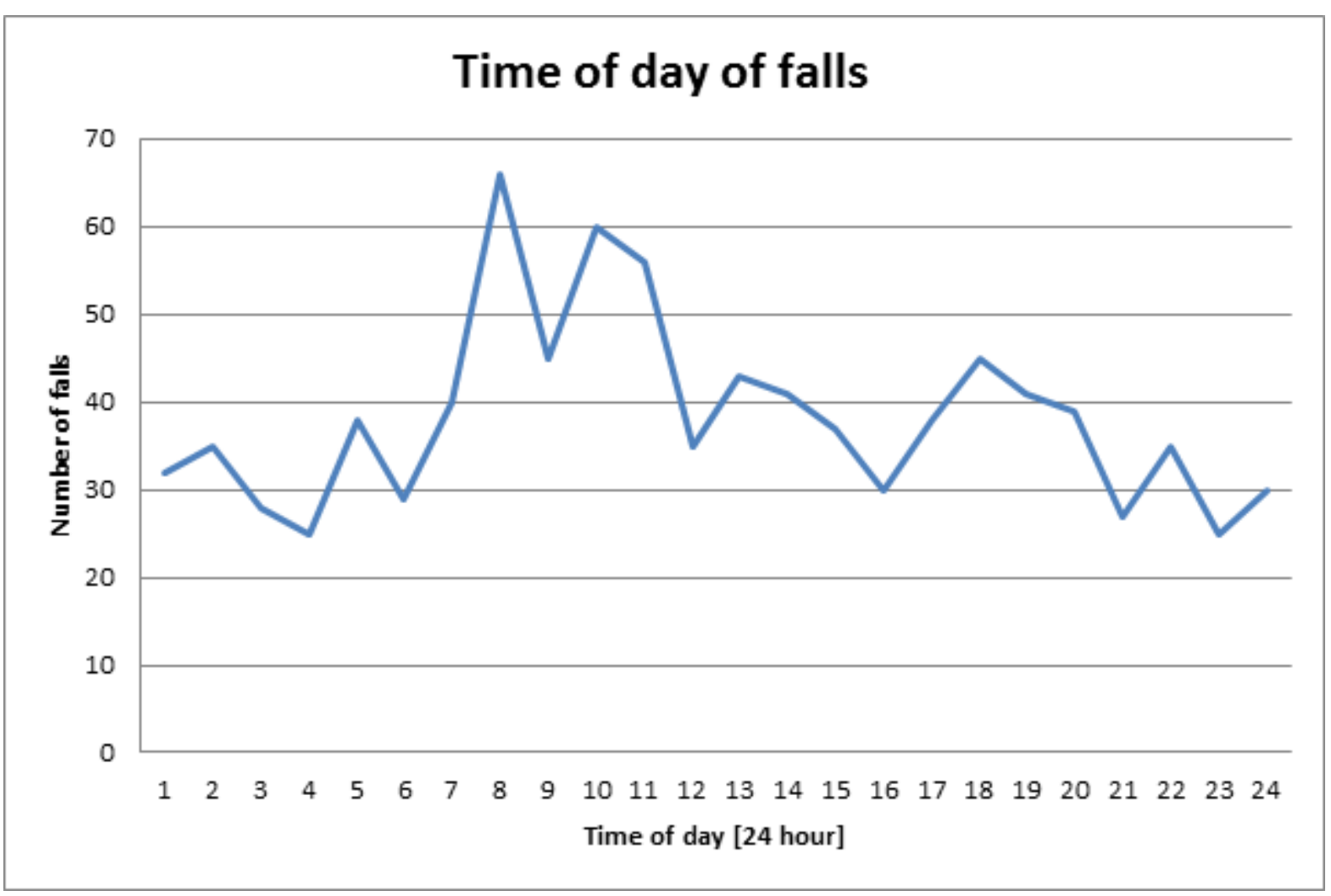

Figure 2: Reported falls at different times of day.

\section{Where do falls happen?}

For 786 falls data were provided by the person reporting the fall as to the location of the fall. Approximately half of falls, $49 \%$, occurred in private spaces (bedrooms; $44 \%$ and $5 \%$ in bathrooms and toilets) and $42 \%$ in 'public spaces' where they might have been more easily observed (day rooms 21\%; corridors $15 \%$; dining rooms $3 \%$ ); $7 \%$ occurred in unknown locations and $1 \%$ when patients were outside of the ward. Where we could determine from the form both location and whether fall was witnessed we see that $60 \%$ of falls in public spaces were unseen as compared with virtually all, $93 \%$, of those in private spaces (Table 2).

\begin{tabular}{|l|l|l|}
\hline & $\begin{array}{l}\text { Public spaces } \\
\text { (\% of total falls) }\end{array}$ & $\begin{array}{l}\text { Private spaces } \\
\text { (\% of total falls) }\end{array}$ \\
\hline Seen & $142(15.4 \%)$ & $29(3 \%)$ \\
\hline Unseen & $215(23.4 \%)$ & $400(43.5 \%)$ \\
\hline Total & $357(38.9 \%)$ & $429(46.6 \%)$ \\
\hline
\end{tabular}

Table 2: Falls reported in public or private areas, and seen by staff or unseen*.

Note: Excludes all reports where either location of fall or whether seen/unseen not clear or missing from reports $(n=134,14.6 \%)$.

Public areas of building include for example, corridors, day rooms, dining rooms.
Private spaces of building include for example, bedrooms and bathrooms.

\section{Causes of falls}

Staff recorded the primary cause of the fall using both a drop down menu and free text. For 30\% the cause was recorded as 'Found on Floor' (Cause unknown) (Table 3). Where a cause could be determined by staff the major causes of falls were concerned with mobilisation whilst walking or transferring from beds or chairs. Within the incident reports 32 instances of patients whom staff judged to have experienced a 'behavioural' fall were found. There were a number of different events described in the short report accounts, including patients who were thought by staff to have lowered themselves to the floor without injury. This type of 'cause' of a fall is illustrated by this explanation on the falls reporting form "Found (patient) with her head on the ground and on hands and knees. Unsure if (patient) put herself on floor, staff were in room but did not see or hear anything so doubt a fall?"

\begin{tabular}{|l|l|l|}
\hline Cause of Fall* & Frequency & Per cent \\
\hline Found On Floor (Cause Unknown) & 276 & 30.0 \\
\hline While Mobilising / Walking Unassisted & 216 & 23.5 \\
\hline Fall - Other & 124 & 13.5 \\
\hline Slip Trip Fall On Same Level & 95 & 10.3 \\
\hline
\end{tabular}


Citation: Victor C, Dickinson A, Narayanan V, Simpson C, Griffiths C, Humphrey D (2014) Falling in Acute Mental Health Settings for Older People: Who falls, where, when and why?. J Gerontol Geriat Res 3: 173. doi:10.4172/2167-7182.1000173

Page 5 of 8

\begin{tabular}{|l|l|l|}
\hline Fall From Bed & 92 & 10.0 \\
\hline Fall From Chair & 38 & 4.1 \\
\hline Suspected Fall & 22 & 2.4 \\
\hline Faint / Dizziness / Collapsed & 15 & 1.6 \\
\hline Fall from Toilet & 14 & 1.5 \\
\hline Fall from Wheelchair & 9 & 1.0 \\
\hline Assisted To Floor & 8 & 0.9 \\
\hline Unassisted Transfer & 5 & 0.5 \\
\hline Fall From Commode & 4 & 0.4 \\
\hline Assisted Transfer & 1 & 0.1 \\
\hline While Being Transported & 1 & 0.1 \\
\hline Total & 920 & 100.0 \\
\hline
\end{tabular}

\section{Analysis of falls in 2012: Who falls?}

In order to explore these findings in more depth we looked at fall reports for 2012 and identified the individuals who fell in order to examine their characteristics in more detail. In particular we wished to examine how long after admission the fall took place. The 315 fall incidents represented 130 patients with a mean age of 81.7 years (range 59 to 99 years; SD 8.3) of whom $57 \%$ were female (Figure 3). In terms of diagnosis $40 \%$ had a primary functional diagnosis, $46 \%$ an organic mental health diagnosis and for $14 \%$ the diagnosis was nonspecific).

Table 3: Causes of falls as recoded in fall reports.

\section{Outcomes of falls}

Staff reported the outcome of the fall using free text and this was then categorised by the research team. For half (51\%) there was no injury and $11 \%$ the injury status was not reported (see Table 4 ). There was a category described as 'no injury at first' which was used when no physical injuries were apparent immediately following the fall. Some patients were described as being sent to $A \& E(n=8)$, primarily for $X-$ rays $(n=11)$ or for suspected fractures $(n=10)$. The discrepancy in the number sent to $\mathrm{A} \& \mathrm{E}$ and the number receiving an $\mathrm{X}$-ray investigation is because the code 'sent to $A \& E$ ' is used where these words were explicitly included in the incident report form.

\begin{tabular}{|l|l|}
\hline Reported injury & Frequency \\
\hline No apparent physical injury & $470(51 \%)$ \\
\hline No Injury at first & $25(3 \%)$ \\
\hline Injury status not reported & $99(11 \%)$ \\
\hline Injury (including cuts, bruises etc) & $326(35 \%)$ \\
\hline Total & $920(100 \%)$ \\
\hline
\end{tabular}

Table 4: Outcome of falls

Types of injury reported included skin tear/graze (19\%), bruising (11\%), bump/swelling (7\%), and suspected fracture (4\%). Fourteen percent of patients were described as experiencing pain following the fall. Injuries involving the head were most common, with 270 (29\%) of incident reports referring to head injuries of some type, including bumps and cuts. Other places of injury included arm/hand $(\mathrm{n}=141$, $15 \%)$, leg/foot $(n=70,8 \%)$, torso $(n=47,5 \%)$ and hip/bottom $(n=39$, $4 \%)$.

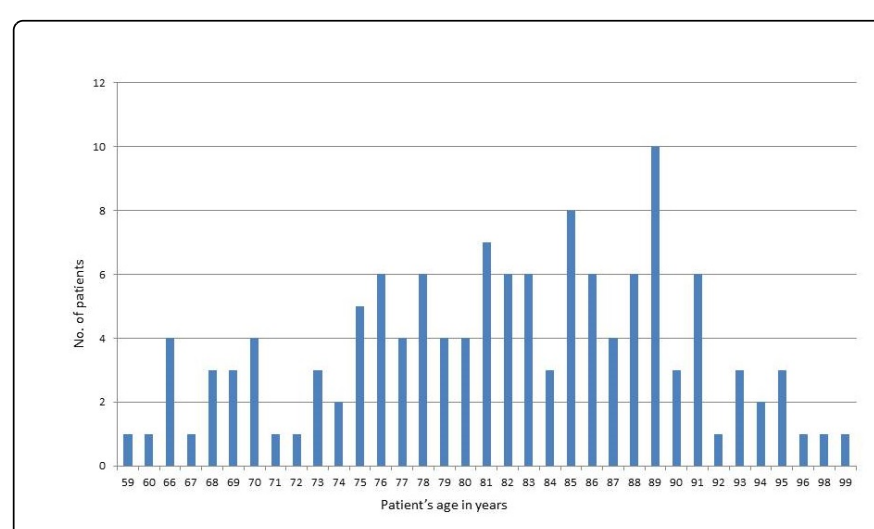

Figure 3: Age distribution of patients who fell in 2012

From the 130 patients, 119 had been discharged when this study ended its data collection phase in 2013 and their length of stay ranged from 3 days to 870 (mean=102; median 86 days and mode 36, SD=98) (Figure 4). If we exclude the four outliers with a length of stay of 250 days or more, the mean length of stay is 90 days (range 3-246; median 8 days; mode $36 ; \mathrm{SD}=60$ ).

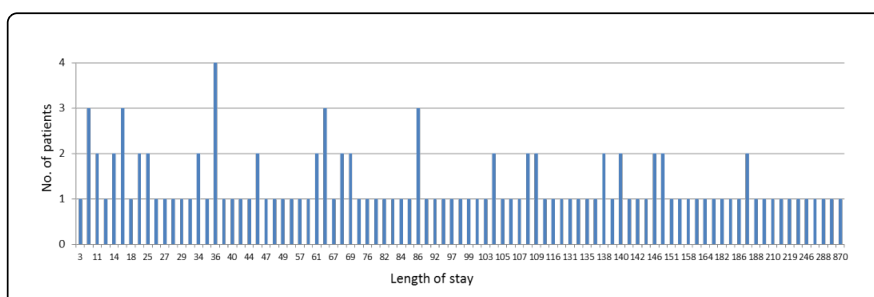

Figure 4: Length of stay in days for patients who fell during 2012

We calculated the average number of days from admission to their first fall. So if a patient fell on the day they were admitted this is classed as 0 days after admission to first fall. The average (mean) time to first fall was 49 days ( $S D=76)$; with a median of 21 days and a mode 13 days (Figure 5). Visual inspection of this figure suggests there were two points post admission where the risk of falling was elevated; day 1 of the admission and day 13. Excluding 3 patients with lengths of stay of 200 days or more gives a mean time to first fall of 40 days $(S D=47)$ with a median of 20 and a mode of 13 . 


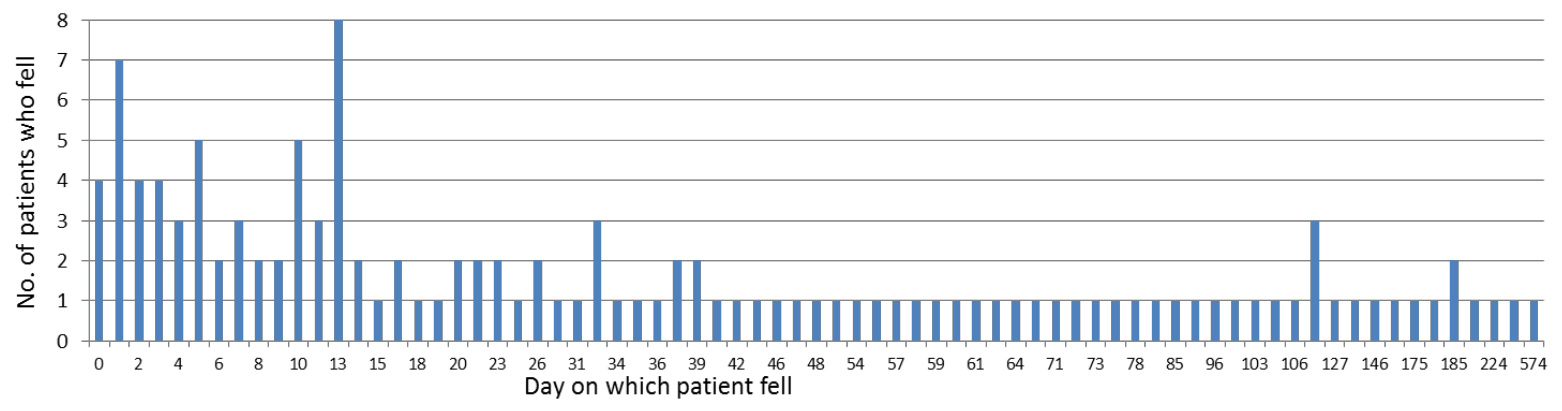

Figure 5: Time from admission to first fall for 2012 (number of days)

Mean days until first fall by diagnosis was also calculated for the 108 patients who had a recorded diagnosis and complete data to calculate time to first fall by diagnostic group. For the 58 patients with an organic diagnosis, the mean days till first fall was 43 (range 0 days to 224, $\mathrm{SD}=52$, mode $=2 \& 5$ ) and 65 days for those with a functional diagnosis $(\mathrm{N}=50$; range 0 days to $574 ; \mathrm{SD}=103$, mode $=5$ \& 13 ). Removing those with a stay of over 200 days reduces our sample sizes to 57 (organic disorders) and 48 (functional disorders) respectively and mean length to first fall to 40 days for the organic disorders group $(\mathrm{SD}=45$; Median=21) and 47 for those with a functional diagnosis ( $\mathrm{SD}=49$; median=35); modes for both groups remained the same even after removing the 'over 200 days' outliers.

\section{Qualitative data}

Data from the focus groups undertaken with staff, allowed staff to explain whether and how they reported falls. For example if a fall is associated with an injury then staff explain that this is always followed by an incident report:... 'if there's an injury, so you need to make an incident report, it needs recorded (sic)'. However, if there is no apparent injury, then staff explained that they may not always complete an incident report (even if the fall had not been observed) but would probably record these kinds of falls in individual patient records (we did not review these for this study). Reasons for noncompletion of incident reports included the time taken for completion of reports, with staff saying they prioritised patient care over filling in reports. For example "but if they sort of just go 'whhhoooaaa' you know and that's it, carry on walking, then I probably would look at why they did that but might not put it in an incident report unless it was something a bit more serious". Slips, trips and near misses were very unlikely to be reported, illustrated by the following member of staff: "It's going to take more people off the floor and there's going to be less time for patient care if everyone's going to be constantly going 'oh, someone just tripped over their own foot, I'm gonna go and document that"'. Staff described difficulties that may be specific to mental health settings, related to reporting falls thought to be deliberate/due to patient's mental health condition/behaviour. Staff had some difficulties defining falls in the mental health population, as they described how some patients may deliberately put themselves on the floor. Previous behaviour of the patient also contributed to decision-making relating to reporting, particularly patients who had previously been seen to put themselves on the floor thus "Yeah, I mean if you've seen them literally in front of your eyes lower themselves to the floor and there's clearly no injury you probably wouldn't do it"; "But you can clearly see if somebody has just sort of put themselves down in a gentle way (people agreeing) that's different and that's very controlled. There may be consequences to that, they may actually have injured themselves but that's sort of the consequence of their behaviour rather than... (people agreeing). Does that make sense? ' ... "a fall is, you know, where you have no control over it, yeah, there is a cause but you have no control over that fall, but for a person to place themselves on the floor and they can get up, you know, what I mean they can get up, they put themselves there, they can bring themselves up".

\section{Discussion}

It is well established that falls are a major patient safety issue in hospital settings regardless of the type of health care system. Analysis of the nature and characteristics of those who fall whilst in hospital consistently identify older patients, those with multiple pathology and those with dementia as key groups 'at risk' of falling [11,20,21]. Given this profile it is, therefore, rather surprising that few studies have focused upon falls assessment and prevention/reduction interventions in mental health care settings [17]. As part of a larger study investigating fall assessment and reporting in a Trust providing mental health care for older people this paper has considered the basic distribution of falls within this setting.

All UK NHS Trusts have a routine system of falls reporting although the precise details collected vary across Trusts. There is no 'minimum data set' that all reports are required to include. Whilst falls data are reported to the regulatory authorities these routine reports are predominantly focussed for local use. Thus the incident report forms used in this study and ones reported by Healy et al. [13] and Hignett et al. [19] are all based upon the analysis of data collected for local monitoring/clinical governance reasons and, as such, are typical of the type of data collected by the NHS for routine practice. They are not developed for use by researchers and therefore do not contain all of the variables of interest to researchers. Despite this, analysis of these types of routine data sets offers potential insights into issues such as the experience of patient falls within specific health care settings.

Our analysis, in common with those by Healey [13] and Hignett [19], are based upon routine incident forms completed after a patient has fallen irrespective of whether the fall was observed by staff or not. Previous research has demonstrated that falls, especially the less serious type where there is no injury, are consistently under reported [22]. This under-reporting reflects the complexity of determining when a fall has taken place in a context where the vast majority of falls, $75 \%$ in our study and $78 \%$ in previous studies in England and Wales 
[19] are not observed. In the focus groups we held as part of this study our staff reported the difficulties they had in deciding if a patient had fallen or not. In the clinical setting the simple binary divide that differentiates falls from non-falls is not always easy to operationalise. Clinical staff told us that they would not report all falls which is in line with previous studies [22]. Fall reporting is an area fraught with ambiguity which resulted in variable practice between staff and, potentially, across different settings. Healey et al. report that falls per 1000 bed days for, mental health trusts ranged from 1 to 8 per 1000 bed days (mean 2.9 per 1000 bed days) [14]. In part this reflects the varying case mix across units but also how staff define and document falls. Our study area approximated to the national rate of falls reporting.

In our study fall reporting appears to be affected by a range of factors including different understandings and interpretations of what is meant by a fall. Comments made by staff about the decision making process underpinning falls reporting provide the context within which to interpret our empirical results. In addition a further limitation of our study is that these are routine administrative data and therefore are not designed for research use. One consequence of which is the issue of missing data. Indeed the NPSA report notes that the lack of detail on many fall reports they examined meant that staff/managers could not learn anything in terms of falls prevention from examining the reports. A previous study identified lack of feedback to staff as one of the reasons for poor incident reporting [22], during our study, after one year of analysis of falls incident reports we shared the findings with staff and managers within the NHS Trust and this had the unexpected consequence of improving the quality of reporting in subsequent years with additional narrative detail being provided. As with previous studies the majority of falls were not observed; took place on Tuesday and Saturdays and occurred at key times of getting up/breakfast time; lunch and early evening-all times of peak activities within the ward environment. The majority of fallers fell only once but a minority, one third, was multiple fallers and falls were equally as likely to occur in public and private spaces. A particular characteristic of the mental health setting is that patient populations are more mobile than patients in acute settings, partly for some because of their underlying condition. In addition gait and balance may be compromised by the condition that patients are suffering from and the drugs prescribed to treat these. Thus the greater mobility of the patient population may mean that they are less easy to observe than those in acute wards. Whilst it is not surprising that $93 \%$ of falls in private spaces, mostly bedrooms, were not observed almost two thirds of those in public spaces were not observed which appears counterintuitive as it should be easier to observe patients in these spaces. However observational data revealed that ward geographies affected the ability of staff to observe patients as did ward routines, for example, during the morning staff were in patient rooms assisting them with personal care so were not available to observe patients who had moved from their bedrooms to public areas of the ward. Further exploration of unseen falls has been identified as a priority in the recent UK fall prevention guidelines [6]. Routine mapping of the time and place that falls occur could, however, be undertaken at ward level to identify fall 'hotspots' and to contribute to the planning of care, staffing levels and distribution of staff across the settings concerned. It is not possible to prevent all falls, especially given the vulnerability of the population being cared for in mental health settings where co-morbidity and medications used for mental health conditions may increase the risk of falls. Nationally it is recognized that it is important to ensure that falls are responded to promptly to minimize the risk of serious injury
(National Patient Safety Agency, 2011). Similarly the National Patient Safety Agency report noted that nurses in mental health settings reported that their mental health education had not equipped them to provide optimal care to the increasingly complex pattern of comorbidity presented by older patients in mental health settings [23].

The length of stay for patients in our case study area was long in comparison with acute general settings with a median length of stay of 8 days (mean of 90 days (range 3-246) and a mode of 36 days). Falls were not happening when patients were first admitted to the wards, perhaps there was greater scrutiny of patients when they were first admitted to the wards. The average (mean) time to first fall was 5 weeks with a median of 3 weeks and a mode of 2 weeks. When we separate out those with organic and functional disorders we see that for both groups falls are occuring when patients have been on the ward for lengthy periods. This suggests that falls are not happening in the immediate post admission period when patients are adapting to their new environment but after they have been there for lengthy periods of time. This raises the question of if this pattern is specific to our setting and why falls are occuring such a long time after admission -what factors are triggering these events? The routine fall reporting form is not of use in answering this question which requires further investigation.

In our study focus groups with the staff revealed that each fall is perceived to be different. There was no such thing as a typical or standard fall. Combined with the complexities of determing if a fall was really a fall or a manifestation of the patients' mental health problems further complicated the decision making process in terms of the identification and reporting of falls. Such ambiguities and complexities are not recognised in hospital based falls reporting and prevention policies meaning that there is a 'poor fit' between the daily work of staff and the policy famework for falls reporting within which they operate.

\section{Acknowledgements}

This paper outlines independent research commissioned by the National Institute for Health Research (NIHR) under its Research for Patient Benefit Programme (Grant Reference PB-PG-1208-18211) Risks, roles and responsibilities: Evaluating falls in inpatient mental healthcare settings for older people. The views expressed in this publication are those of the authors and not necessarily those of the NHS, the NIHR or the Department of Health.

We would like to thank the staff, patients and family carers who kindly participated in this study and Dr. Wendy Martin for her contribution to the study.

\section{References}

1. Rubenstein LZ [2006] Falls in older people: epidemiology, risk factors and strategies for prevention. Age and Ageing 35: 37-41.

2. Yardley L, Donovan-Hall M, Francis K, Todd C [2006] Older people's views of advice about falls prevention: a qualitative study. Health Education Research 21: 508-517.

3. Cumming RG, Salkeld G, Thomas M, Szonyi G [2000] Prospective Study of the Impact of Fear of Falling on Activities of Daily Living, SF-36 Scores, and Nursing Home Admission. The Journals of Gerontology Series A: Biological Sciences and Medical Sciences 55: 299-305.

4. Murphy SW, Gill TM [2002] Characteristics associated with fear of falling and activity restriction in community-living older persons. J Am Geriatr Soc 50: 516-520. 
Citation: Victor C, Dickinson A, Narayanan V, Simpson C, Griffiths C, Humphrey D (2014) Falling in Acute Mental Health Settings for Older People: Who falls, where, when and why?. J Gerontol Geriat Res 3: 173. doi:10.4172/2167-7182.1000173

Page 8 of 8

5. Vass CS, Drummond O, Kendrick A, Grainge D, Sach M, Gladman T, Avis J [2013] REFINE- REducing Falls in In-patieNt Elderly using Bed and Chair Pressure Sensors in Acute Hospital Care: A Randomised Controlled Trial. Age and Ageing 42: 20-22.

6. National Institute of Health and Care Excellence [NICE] [2013] Falls: assessment and prevention of falls in older people. NICE clinica guideline 161. Manchester: National Institute for Health and Care Excellence.

7. The Australian Commission on Safety and Quality in Health Care. Preventing Falls and Harm From Falls in Older People: Best Practice Guidelines for Australian Hospitals. Commonwealth of Australia: The Australian Commission on Safety and Quality in Health Care, 2009.

8. Winnipeg Regional Health Authority. Falls Prevention and Management Regional Clinical Practice Guidelines. Canada: Winnipeg Regional Health Authority, 2011.

9. Panel on Prevention of Falls in Older Persons AGS, British Geriatrics S. Summary of the Updated American Geriatrics Society/British Geriatrics Society Clinical Practice Guideline for Prevention of Falls in Older Persons. Journal of the American Geriatrics Society. 59: 148-57.

10. Beauchet o, dubost $\mathrm{v}$, revel-delhom c, et al. [2011] How to manage recurrent falls in clinical practice: guidelines of the french society of geriatrics and gerontology.

11. Johansson I, Bachrach-Lindström M, Struksnes S, Hedelin B [2009] Balancing integrity vs. risk of falling -nurses' experiences of caring for elderly people with dementia in nursing homes. Journal of Research in Nursing 14: 61-73.

12. Joo JL, Mulsant EJ, Begley BH, Weber AE, Stack EM, Mazumdar JA, Reynolds S, Pollock CF [2000] Risk factors for falls during treatment of late-life depression 63: 936-941.

13. Healey F, Scobie S, Oliver D, Pryce A, Thomson R, Glampson B [2008] Falls in English and Welsh hospitals: a national observational study based on retrospective analysis of 12 months of patient safety incident reports. Quality and Safety in Health Care 17: 424-430.
14. National Patient Safety Agency. Slips trips and falls data update NPSA 2010.

15. Heslop K, Wynaden D, Bramanis K, Connolly C, Gee T, Griffiths R, et al. [2012] Assessing falls risk in older adult mental health patients: A Western Australian review. International Journal of Mental Health Nursing 21: 567-575.

16. Hill AM, Hoffmann T, Hill K, Oliver D, Beer C, McPhail S, et al. [2010] Measuring falls events in acute hospitals-a comparison of three reporting methods to identify missing data in the hospital reporting system. J Am Geriatr Soc 58: 1347-1352.

17. Bunn F, Dickinson A, Simpson C, Narayanan V, Humphrey D, Griffiths C, et al. [2014] Preventing falls among older people with mental health problems: a systematic review. BMC Nurs 13: 4 .

18. Johnson M, George A, Tran DT [2011] Analysis of falls incidents: Nurse and patient preventive behaviours. International Journal of Nursing Practice 17: 60-66.

19. Hignett S, Sands G, Griffiths P [2011] Exploring the contributory factors for un-witnessed in-patient falls from the National Reporting and Learning System database. Age and Ageing 40:135-138.

20. Struksnes S, Bachrach-Lindstrom M, Hall-Lord M, Slaasletten $R$, Johansson I [2011] The nursing staff's opinion of falls among older persons with dementia. a cross-sectional study 10: 13 .

21. Damian J, Pastor-Barriuso R, Valderrama-Gama E, de Pedro-Cuesta J [2013] Factors associated with falls among older adults living in institutions. BMC Geriatrics 13: 6 .

22. Evans SM, Berry JG, Smith BJ, Esterman A, Selim P, O'Shaughnessy J, et al. [2006] Attitudes and barriers to incident reporting: a collaborative hospital study. Qual Saf Health Care 15: 39-43.

23. National Patient Safety Agency. Essential care after an inpatient fall. National Patient Safety Agency.
This article was originally published in a special issue, entitled: "Fall prevention", Edited by Hiroyuki Umegaki, Department of Geriatrics Nagoya University Graduate School of Medicine, Japan 